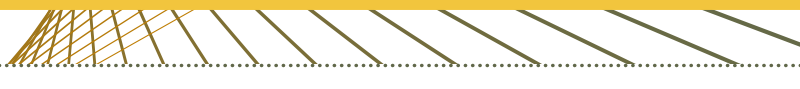

\section{La protección de las mujeres en Colombia, un análisis en el marco del conflicto armado}

Protection of women in Colombia, an analysis in the context of the armed conflict
Diana Patricia Ortega García ${ }^{1}$

diana.ortega@uniremington.edu.co

https://orcid.org/0000-0001-6020-9090

https://doi.org/10.22209/rhs.v8n1a03

Recibido: marzo 12 de 2020.

Aceptado: junio 12 de 2020.

\section{R e s u m e n}

El conflicto armado colombiano es el único enfrentamiento originado en el siglo xx que aún permanece activo en el continente americano y cuya principal característica son los combates entre grupos armados de izquierda y derecha, en contra del gobierno nacional. En medio de los combates, la población civil ha sido la principal víctima, pero en su interior han sido las mujeres quienes mayores consecuencias han sufrido. A través de una revisión literaria sobre el tema, el presente escrito aborda la estructura normativa e institucional que tienen las mujeres colombianas para la protección de sus derechos en el marco del conflicto armado. Los resultados muestran que, a pesar de la existencia de leyes nacionales e instrumentos internacionales para su protección, la cultura patriarcal arraigada en la sociedad colombiana y la misma

1 Docente de la Dirección de Humanidades, Corporación Universitaria Remington. dinámica del sistema de justicia generan que no exista seguridad jurídica respecto a la protección de la integridad de la población femenina en el contexto nacional.

Palabras clave: Colombia; conflicto armado; delitos sexuales; derechos humanos; justicia; mujeres.

\section{Abstract}

The Colombian armed conflict is the only confrontation originated in the 20th century that is still running active in the American continent, whose main feature is the combat between left-and-rightwing armed groups and the national government. In the midst of the confrontation, civilians have been the main victims, particularly women, who have suffered the greatest consequences. Through a review of literature, this paper presents the regulatory and institutional structure available to Colombian women for protecting their rights in the context of the armed conflict. The results show that, while national and international laws are in place to protect women's rights, the patriarchal culture rooted in Colombian society as well as the dynamics of the domestic justice system result in the lack of legal certainty for protecting the integrity of Colombian women.

Keywords: Colombia; armed conflict; sexual crimes; human rights; justice; women. 


\section{Introducción}

E n un contexto de conflicto armado, la violencia en contra de las mujeres es una práctica constante, pues además de ser víctimas de diversos tipos de violencia, sus cuerpos son transformados en territorio de guerra y estrategia para atacar al enemigo. El conflicto armado colombiano no ha sido ajeno a esta práctica y la población femenina del país ha sufrido diferentes formas de violencia armada que, sumadas a una cultura patriarcal, la han ubicado en un papel de inferioridad social.

En el marco de los enfrentamientos entre grupos de izquierda y de derecha, y de estos en contra del Estado, las mujeres colombianas han sido victimizadas por todos los tipos de actores armados, pero no han encontrado ni la protección ni la atención que requieren por parte de las instituciones gubernamentales, pues al ser sus derechos vulnerados deben acudir a un sistema judicial que no les brinda la atención correcta, que las revictimiza o las obliga a sufrir en silencio las consecuencias de los atropellos cometidos en contra de sus derechos. Aun quienes logran obtener atención, representan un porcentaje muy pequeño del total de víctimas que han generado las dinámicas del conflicto.

Esta situación se presenta en un contexto jurídico que cuenta con estrategias específicas de protección y atención hacia esta población, las cuales responden a la obligación jurídica que emana de la constitución nacional y los derechos que esta determina tanto para hombres y mujeres. Así mismo, el gobierno nacional posee responsabilidad jurídica internacional para la protección de las mujeres tanto en el marco del conflicto como en contextos de normalidad. Sin embargo, ni la normativa nacional ni la internacional han logrado garantizar la completa protección de los derechos de las mujeres en el territorio colombiano.

Dicho esto, el presente escrito tiene por objetivo exponer la violencia en contra de la mujer en el marco del conflicto armado colombiano, a través de la descripción de sus características y el análisis de los instrumentos jurídicos nacionales e internacionales que existen para su persecución, investigación y sanción, de tal forma que se evidencie su aplicabilidad por parte de las instituciones correspondientes y la efectividad para dar atención a las víctimas.

\section{Materiales y métodos}

Esta investigación se desarrolla a través de un método descriptivo, en la medida que es necesario detallar la violencia hacia la mujer en el marco del conflicto y los instrumentos jurídicos nacionales e internacionales aplicables a este contexto. El proceso investigativo utiliza un diseño documental con un enfoque sistémico a través de la recopilación de datos, resultado de la revisión literaria relevante acerca del tema de estudio y la información que proveen diversas fuentes gubernamentales, no gubernamentales y organizaciones internacionales.

\section{Resultados}

La protección jurídica hacia la mujer colombiana emana en principio de la Constitución Política de Colombia de 1991 (Const., 1991), que establece que el país es un Estado social de derecho, lo que significa que es el Estado el encargado de dar protección a la población, de atender sus requerimientos y de garantizar y promover sus derechos fundamentales. El 
documento determina que el derecho a la vida es inviolable (art. 11), que la desaparición forzada, la tortura y los tratos crueles, inhumanos o degradantes están prohibidos (art. 12); y que todas las personas nacen libres e iguales ante la ley (art. 13). De igual forma, establece que la esclavitud, la servidumbre y la trata de seres humanos en todas sus formas están prohibidas (art. 17) y que el derecho a la honra debe ser garantizado (art. 21).

Estos apartados de la constitución fundamentan un ordenamiento jurídico colombiano con unos derechos mínimos, que bajo el artículo 43 del mismo documento, deben ser garantizados en igualdad de derechos y oportunidades para mujeres y hombres, haciendo énfasis en que la mujer no puede ser sometida a ninguna clase de discriminación. Considerando la existencia de un conflicto armado interno por más de sesenta años, junto a la constitución existen otras leyes e instrumentos que se enfocan en la protección de las mujeres en el marco de los enfrentamientos:

- La Ley 1719 de 2014, que establece medidas para garantizar el acceso a la justicia de las víctimas de violencia sexual, en especial la violencia sexual con ocasión del conflicto armado. Esta ley no limita la violencia sexual hacia el abuso físico y sexual, sino que incluye otros delitos como el aborto forzado y la esclavitud sexual.

- La Ley 975 de 2005 o Ley de Justicia y Paz que definió el sistema de justicia transicional para la desmovilización y desarme de las Autodefensas Unidas de Colombia.

- La Ley 1148 de 2011 o Ley de Víctimas y Restitución de Tierras que establece medidas específicas de atención y reparación para las víctimas del conflicto armado.
Esta hace especial énfasis en la atención preferencial que deben recibir las mujeres en los trámites administrativos y judiciales del proceso de restitución, y privilegia a las mujeres cabeza de familia y en condición de desplazadas.

- El acuerdo general para la terminación del conflicto y la construcción de una paz estable y duradera, suscrito entre el gobierno colombiano y el grupo guerrillero de las Fuerzas Armadas Revolucionarias de Colombia, Ejército del Pueblo (FARC-EP) en el año 2016. ${ }^{2}$ El acuerdo incluye entre sus principios la igualdad y el enfoque de género, a través del cual se reconocen las necesidades específicas y diferenciales de las mujeres, lo que implica la adopción de medidas especiales para dar cumplimiento a lo acordado.

A este ordenamiento interno se suman instrumentos jurídicos internacionales ratificados por el Estado colombiano aplicables en contextos, tanto de conflicto armado como de normalidad, cuyo objetivo principal es la protección hacia las mujeres. Entre los principales se identifican: ${ }^{3}$

- Convención Interamericana sobre la concesión de los derechos civiles de la mujer de 1948, ratificada a través de la Ley núm. 8 de 1959.

2 La Proposición núm. 83, publicada en la Gaceta núm. 39 del Congreso, el 7 de febrero de 2017, da cuenta de que, en ejercicio del artículo 248 de la Ley núm. 5 de 1992, el Senado de la República decidió la refrendación del acuerdo final por parte del Congreso de la República.

3 Leyes colombianas en materia de protección hacia las mujeres. Disponible en: http://www.suin-juriscol.gov.co/legislacion/diadelamujer.html 
- Convención sobre la eliminación de todas las formas de discriminación contra la mujer de 1979, ratificada por la Ley núm. 51 de 1981.

- Convención Interamericana para prevenir, sancionar y erradicar la violencia contra la mujer de 1994, ratificada por la Ley núm. 248 de 1995.

Otros documentos internacionales firmados y ratificados por Colombia que, sin enfocarse específicamente en la población de mujeres, también son instrumentos para su protección, especialmente en contextos de conflictos, son:

- Pacto de los Derechos Civiles y Políticos y el Pacto de los Derechos Económicos, Sociales y Culturales, ambos de 1966, a través de la Ley núm. 74 de 1968 y cuya entrada en vigor se dio en enero de 1976.

- Convención Americana sobre Derechos Humanos o «Pacto de San José de Costa Rica» de 1969, por medio de la Ley núm. 16 de 1972.

- Cuatro Convenios de Ginebra y sus dos protocolos adicionales, el primero ratificado en 1993 y el segundo en 1995.

- Estatuto de Roma, ratificado por el Congreso de la República a través de la Ley núm. 724 de 2002, la cual está legitimada por la Corte Constitucional a través de la sentencia C-578/02 del mismo año.

Cada uno de estos documentos da cuenta de que el ordenamiento jurídico colombiano posee una obligación nacional e internacional para proteger los derechos de las mujeres, tanto en tiempo de conflicto como por fuera de él. Sin embargo, su existencia no es sinónimo de eficacia, pues la realidad de esta protección está lejos de la obligación, especialmente bajo un sistema de justicia poco efectivo y en el marco de un conflicto con tantas particularidades como el colombiano.

Al respecto, el informe ¡Basta ya! Colombia, Memorias de Guerra y Dignidad, afirma que «la estigmatización y revictimización que ocurren tanto en ámbitos sociales como institucionales han inhibido la denuncia y silenciados los hechos» (Grupo de Memoria Histórica [GMH], 2013 , p. 77). Los estudios del grupo describen testimonios de mujeres que denuncian como algunos funcionarios no creyeron la veracidad de los hechos violentos, al estar inspirados en representaciones estereotipadas de la violencia sexual o al reproducir prejuicios que desestiman lo narrado por las víctimas. Este tipo de fallas genera que las mujeres víctimas decidan no denunciar las agresiones, pues el mismo proceso de investigación las revictimiza o las sanciones impuestas tienen altos grados de impunidad.

Para la Corte Constitucional colombiana, a través de Auto 092 (Chaparro, 2013), entre los problemas judiciales para dar castigo a los crímenes cometidos en contra de las mujeres en el marco del conflicto, se encuentran los obstáculos asociados a la desconfianza de las mujeres en el Estado, la vergüenza, el desconocimiento de los procedimientos, la debilidad de las instituciones, la influencia de los estereotipos de género, la presencia de actores armados y la dificultad de las mujeres para el ejercicio de sus derechos (p. 37).

Por otra parte, las características particulares del conflicto armado colombiano también dificultan el acceso a la justicia por parte de las mujeres. En ese sentido, el enfrentamiento se caracteriza porque el gobierno nacional no se enfrenta solo a un grupo rebelde que está en contra del orden establecido, sino que 
también existen otros fenómenos subversivos e ilegales que generan inestabilidad en el país. Cada uno de los actores involucrados, tanto los grupos de izquierda y derecha como los carteles del narcotráfico, así como las mismas fuerzas del Estado, han sido victimarios a lo largo del conflicto.

Sobre el tema, el primer capítulo del informe del Grupo de Memoria Histórica se dedica a la descripción del uso de catorce modalidades de violencia cuya principal víctima ha sido la población civil. Entre estas se encuentran los asesinatos selectivos, el secuestro, las masacres, las desapariciones forzadas, el desplazamiento forzado, la tortura y sevicia, las minas anti persona, la violencia sexual, el reclutamiento de menores de edad, los atentados terroristas, los ataques a bienes civiles, las amenazas, acciones bélicas, entre otros, que fueron cometidos por los diversos actores al margen de la ley y por miembros de las fuerzas estatales.

«En las mujeres, estos hechos de violencia han dejado huellas profundas y diferenciales en sus cuerpos y en su psiquis, han trastocado su cotidianidad y han alterado sustancialmente sus creencias y sus formas y proyectos de vida» (GMH, 2013, p. 305). En ese orden de ideas, la violencia contra la mujer en Colombia se expresa principalmente a través de la cultura patriarcal, la cual se profundiza en el contexto de la guerra. Sánchez (2008), al trasladar este problema al conflicto armado, afirma que:

El poder patriarcal se materializa al convertir el cuerpo de las mujeres en territorio que se disputan los actores armados, ya que la cultura militar valora y refuerza los estereotipos machistas y subvalora las cualidades que se le atribuyen a la mujer. (p. 65)
De acuerdo con Restrepo Yepes (2007):

Entre los principales tipos de violencia ejercida por los actores armados en CoIombia hacia la población femenina son la violación y esclavitud sexual, el uso obligatorio de métodos anticonceptivos y abortos, la imposición de trabajos domésticos forzados y su marginación en la participación en la vida pública. (p. 91)

La analista añade que «la mayoría de las mujeres y niñas afectadas son campesinas, indígenas, afrocolombianas y desplazadas, que son discriminadas no solo por su género, sino también por su origen étnico» (p. 91). Otros actos violentos fueron:

Las violaciones masivas y múltiples, violaciones a mujeres privadas de su libertad, mutilación de órganos sexuales femeninos, mutilación de los fetos de las mujeres embarazadas, actos humillantes y degradantes, esclavitud sexual, embarazos forzados y persecución a lesbianas, travestis, prostitutas y gays. (Sánchez, 2008, p. 68)

Al citar el auto 092 de 2008, la Unidad para la Atención y la Reparación Integral a las Víctimas (s.f.) afirma que:

Las mujeres colombianas están expuestas a diez riesgos de género en el marco del conflicto armado: violencia sexual, explotación sexual o abuso sexual; explotación para ejercer labores domésticas; reclutamiento forzado de sus hijos e hijas por los actores armados; contacto de las relaciones familiares o personas con los integrantes de un grupo armado ilegal o fuerza pública; afectaciones por su pertenencia a organizaciones sociales, 
comunitarias o políticas de mujeres; persecución y asesinato por las estrategias de control coercitivo; asesinato o desaparición de su proveedor económico; despojo de sus tierras; discriminación y vulnerabilidad; y pérdida o ausencia de su compañero o proveedor económico durante el proceso de desplazamiento. (p. 9)

Estos actos de violencia en contra de la mujer en el marco del conflicto armado colombiano han sido perpetrados por todos los actores armados, sin embargo, esta tiene mayor prevalencia entre los grupos paramilitares quienes la usan con el objetivo de:

Atacar a mujeres por su condición de liderazgo, para destruir el circulo afectivo de aquellos considerados como enemigos, para "castigar» conductas transgresoras desde la perspectiva del actor armado, como asociación a prácticas culturales y orientada a generar cohesión entre los integrantes del grupo y el afianzamiento de sus identidades violentas. (GMH, 2013, p. 80)

En cuanto a los grupos guerrilleros y miembros de la fuerza pública, los mismos estudios evidencian que el uso de la violencia sexual por parte de estos actores se clasifica como oportunista, al no estar ligado a la consecución de objetivos militares o estratégicos, no obstante, al interior de los grupos guerrilleros se identificó que existen prácticas obligatorias como el uso de métodos anticonceptivos y el aborto forzado (GMH, 2013).

Los hechos violentos en el marco de un conflicto armado pueden generar afectaciones emocionales, psicológicas y sociales, pero cuando se hace referencia a los delitos sexuales, se identifican consecuencias como enfermedades de trasmisión sexual, lesiones en los órganos genitales, embarazos no deseados, aborto, complicaciones ginecológicas, cambios en los órganos sexuales y dolores de cabeza frecuentes (Unidad para la Atención y la Reparación Integral a las Víctimas, s.f.). A esto se suman sentimientos de culpa y vergüenza, considerando que la sociedad colombiana tiende a estigmatizar y aislar socialmente a las mujeres víctimas de este tipo de actos.

En ese orden de ideas, el Registro Único de Víctimas (RUV), adscrito a la Unidad para la Atención y Reparación Integral a las Víctimas, registra desde el $1^{\circ}$ de enero de 1985 y el 26 de junio de 2020, las siguientes cifras y hechos violentos en contra de mujeres (Tabla 1): 
Tabla 1. Número de víctimas de hechos violentos en el conflicto armado colombiano

(entre el $1^{\circ}$ de enero de 1985 y el 26 de junio de 2020)

\begin{tabular}{|c|c|c|}
\hline HECHO & MUJERES & HOMBRES \\
\hline Abandono o Despojo forzado de tierras & 13.088 & 13.028 \\
\hline $\begin{array}{l}\text { Acto terrorista / Atentados / Combates / } \\
\text { Enfrentamientos / Hostigamientos }\end{array}$ & 42.313 & 51.029 \\
\hline Amenaza & 275.115 & 257.273 \\
\hline Confinamiento & 22.518 & 23.411 \\
\hline $\begin{array}{l}\text { Delitos contra la libertad y la integridad } \\
\text { sexual en desarrollo del conflicto armado }\end{array}$ & 30.651 & 2.477 \\
\hline Desaparición forzada & 91.584 & 101.603 \\
\hline Desplazamiento forzado & 4.624 .638 & 4.325 .377 \\
\hline Homicidio & 537.012 & 592.640 \\
\hline Lesiones personales físicas & 3.127 & 6.595 \\
\hline Lesiones personales psicológicas & 5.455 & 10.572 \\
\hline $\begin{array}{l}\text { Minas antipersonal, munición sin explotar } \\
\text { y artefacto explosivo improvisado }\end{array}$ & 1.167 & 10.839 \\
\hline Perdida de bienes muebles o inmuebles & 62.788 & 66.628 \\
\hline Secuestro & 9.660 & 29.083 \\
\hline Sin información & 9.632 & 9.338 \\
\hline Tortura & 4.654 & 6.251 \\
\hline $\begin{array}{l}\text { Vinculación de niños niñas y adolescentes } \\
\text { a actividades relacionadas con grupos } \\
\text { armados }\end{array}$ & 3.019 & 5.885 \\
\hline Total & 5.736 .421 & 5.512 .029 \\
\hline
\end{tabular}

Nota. Construcción propia a partir de los datos del Registro Único de Víctimas

(Unidad para la Atención y la Reparación Integral a las Víctimas, 2020).

Esta información muestra que el número de víctimas es mayor entre las mujeres, siendo el desplazamiento forzado, el homicidio y las amenazas, los hechos violentos que más las afectan, situación que se presenta con las mismas tendencias entre hombres. En la mayoría de actos violentos se evidencian datos similares, lo que muestra que estos son realizados como estrategia de guerra por parte de los actores subversivos, tanto hacia hombres como mujeres, sin hacer distinción de las consecuencias que pueda generar según el género. Sin embargo, en las cifras que se presentan para los delitos contra la integridad sexual, la diferencia entre los datos de mujeres y hombres es bastante amplia, de lo cual se concluye que es un tipo de violencia cuyo uso se define por la identidad de género de la víctima.

Ante este panorama, la Unidad para la Atención y la Reparación Integral a las Víctimas (2018), con el apoyo de ONU Mujeres Colombia, afirma que, hasta al 30 de septiembre de 2017, 7009 indemnizaciones administrativas fueron entregadas a las mujeres víctimas de delitos contra la libertad e integridad sexual 
por un valor de aproximadamente ciento treinta y cuatro mil millones de pesos. Estas cifras muestran una atención importante y el trabajo conjunto de varias instituciones colombianas para brindar justicia y reparación a las víctimas, aunque no termina siendo suficiente. Más de 50 años de conflicto y la evolución de la violencia en el país, dificultan que todas las mujeres víctimas reciban atención, más cuando existe un claro subregistro de los delitos.

Al respecto, el Centro Nacional de Memoria Histórica (2017) afirma que el acceso a la justicia que tienen las mujeres es de poca efectividad y de un gran desgaste emocional, así como de altos riesgos para su seguridad, lo que se traduce en que muchas de ellas no denuncian, ya que existe un miedo justificado de la retaliación del grupo armado y la desconfianza en el trámite judicial. En este sentido, las mujeres encuentran diversos obstáculos en los procesos de denuncia, como la estigmatización en sus comunidades, el desconocimiento del código propio del sistema judicial, la revictimización o la inadecuada tipificación de los delitos (Moncayo, 2009).

Estos obstáculos se presentan ante un gobierno nacional que cuenta con todo un sistema de atención hacia las mujeres víctimas del conflicto colombiano, que incluye legislación directa e indirecta y que está compuesto por instituciones gubernamentales, no gubernamentales e internacionales, que a través de diversas estrategias brindan asistencia, justicia y reparación a esta población. Entre las instituciones públicas y privadas que trabajan para dar atención a las mujeres víctimas del conflicto se identifica inicialmente a la Unidad para la Atención y la Reparación Integral a las Víctimas, creada por la Ley de Víctimas y Restitución de Tierras, que brinda atención a todas las víctimas de conflicto y a través de diversos mecanismos y les otorga reparación por los sufrimientos ocurridos en el marco de los enfrentamientos.

Por otra parte, la Presidencia de la República cuenta con la Consejería Presidencial para la Equidad de la Mujer, creada por el Decreto 1649 de 2014 y que asiste al gobierno en el diseño de políticas destinadas a promover, defender y garantizar los derechos humanos de la población femenina. Específicamente para las víctimas del conflicto, esta institución presta apoyo al Sistema Nacional de Atención y Reparación integral a las Víctimas, al generar espacios de diálogo y trabajo con organizaciones no gubernamentales y asesorar a la presidencia y demás instituciones gubernamentales en los temas relacionados con la correcta aplicación del Derecho Internacional Humanitario.

Así mismo, existen otras instituciones como organizaciones no gubernamentales que también prestan atención a las mujeres víctimas de la violencia del conflicto, más cuando existe cierto nivel de desatención hacia gran parte de esta población. Entre estas organizaciones se destaca Ruta Pacífica de las Mujeres, Sisma Mujer, Casa de la Mujer y Red Nacional de Mujeres. ${ }^{4}$ La mayoría de estas organizaciones nació entre las décadas de 1980 y 1990, en la época en la cual las dinámicas del conflicto fueron más graves, cuando se presentaban las violaciones más graves hacia los derechos de las mujeres y existía menor atención hacia las mismas, por lo tanto, su trabajo ha tenido un alto impacto en el acompañamiento y reparación de las víctimas.

\footnotetext{
4 Organizaciones de mujeres: http://www.equidadmujer.gov. co/consejeria/Paginas/organizaciones-mujeres.aspx
} 
En Colombia hay, además, presencia de organizaciones internacionales que se especializan en dar atención a las mujeres en el contexto humanitario que se presenta en el país. Así, se identifica el trabajo del Comité Internacional de la Cruz Roja, que brinda apoyo al gobierno nacional en el marco del conflicto y hacia toda la población en general; y ONU Mujeres y otras agencias del sistema de Naciones Unidas, cuyas temáticas de acción incluyen la violencia hacia las mujeres y la superación del conflicto armado. ${ }^{5}$

Al considerar la naturaleza, particularidades y prolongación del conflicto armado, la existencia de este sistema es completamente necesario y se puede afirmar que sus acciones han logrado aliviar de cierta forma el sufrimiento de la población femenina; no obstante, su existencia no es suficiente, y se reconoce que el mismo tiene varias falencias que no permiten atender a todas las víctimas. A esto se suma el subregistro de los delitos, la cultura patriarcal presente en el país y las falencias del sistema judicial, que dificultan llegar a un contexto a nivel nacional de cero tolerancia de la violencia contra la mujer.

En ese orden de ideas, la atención hacia las mujeres víctimas de violencia debe partir, inicialmente, de la atención que el Estado les debe garantizar. Al respecto, Amnistía Internacional (2004) afirma que los siguientes son servicios imprescindibles que las instituciones públicas deben ofrecer de forma gratuita:

Asistencia médica inmediata para la atención de las heridas y lesiones, seguimiento

5 Estrategia País ONU Mujeres Colombia. Disponible en: http://colombia.unwomen.org/es/como-trabajamos/ estrategia-pais-2017-2019 médico para la atención de las consecuencias clínicas del acto violento, provisión inmediata de anticoncepción de emergencia y tratamiento profiláctico para evitar el contagio de enfermedades de transmisión sexual; atención psicológica inmediata e intervención de crisis para la víctima y su familia; apoyo psicológico especializado para abordar el trauma; asistencia médico-legal; asistencia social; y medidas de protección para poner a la víctima a salvo de los agresores. (p. 36)

Estos servicios deben estar acompañados de la atención psicosocial de las mujeres víctimas de violencia, especialmente la sexual, la cual debe incluir la perspectiva de género, que permite comprender que esta violencia afecta a las mujeres de una forma específica; de un enfoque feminista, que reconoce que esta violencia se comete en una cultura que tradicionalmente ha validado la inferioridad femenina; de un enfoque en derechos humanos, que reafirme que entre los derechos de las mujeres se incluyen los derechos sexuales y reproductivos; y en un contexto político que rechace la guerra y no ofrezca beneficios penales hacia los victimarios cuando exista un contexto de negociaciones de paz (Wilches, 2010).

En entrevistas realizadas a 935 mujeres víctimas de violación a sus derechos, Arnoso, Cárdenas, Beristain y Afonso (2017), encontraron que esta población considera que es imposible reparar los daños sufridos, pero que el apoyo psicosocial junto a medidas de tipo distributivo para mejorar sus condiciones de vida y medidas de verdad, justicia y protección, son estrategias que aportan en el proceso de superación del dolor. Sin embargo, en un contexto tan complejo como el colombiano, en el cual el sistema de salud es deficiente, 
la educación no llega a toda la población, las oportunidades laborales son limitadas y la desigualdad social profundiza los problemas de la población, la garantía de estos servicios no es prioridad del Estado.

En tal sentido, una verdadera estrategia de atención a las mujeres víctimas de la violencia debe partir de una solución integral que aborde aspectos jurídicos, psicológicos, sociales, económicos y políticos, que no solo se centren en la atención posterior a la comisión del hecho victimizante, sino que también transformen la estructura de la sociedad en la que tomó lugar. Como primer paso, es necesario replantear los procesos educativos y el enfoque de género que tienen, de tal forma que la educación que reciben tanto mujeres como hombres reconozca todos los derechos de la población femenina, y a esta como actor clave en el interior de cualquier sociedad. Esos procesos educativos deben incluir de forma obligatoria la educación sexual y la educación en derechos humanos.

Sin embargo, esto no modifica las prácticas patriarcales que permanecen en el contexto cultural colombiano, especialmente aquellas que afectan los procesos judiciales y de atención en salud hacia las mujeres víctimas, por lo cual también es necesaria la correcta capacitación de los agentes que se encargan de atender, investigar y sancionar los delitos que afectan su dignidad e integridad; esto, enmarcado en una legislación nacional, que no solo reconozca el sufrimiento de las mujeres, sino que también se enfoque en brindarles fácil acceso a todos los servicios que requieren.

Todas estas estrategias se deben acompañar de la efectiva superación del conflicto armado, que debe estar acompañada de procesos de verdad, justicia, reparación y garantías de no repetición. No obstante, al considerar la duración del conflicto armado y las dificultades existentes para esa misma superación, es indispensable que las mujeres sean incluidas como actores partícipes de los procesos de negociación, superación de los enfrentamientos y construcción de paz. Al respecto, Abril (2011) afirma que tradicionalmente las mujeres han sido tratadas como sujetos pasivos en las políticas de paz y seguridad, lo que les impide el acceso a puestos de responsabilidad, decisión política y participación en aspectos que afectan sus intereses y necesidades. En el marco del conflicto, las mujeres han sido víctimas, pero son mucho más que eso, son actores de cambio y transformación de la sociedad colombiana.

\section{Conclusiones}

Las mujeres colombianas que han sido víctimas de los estragos del conflicto armado durante más de sesenta años lo han sido no solo como madres, hijas, hermanas, esposas o allegadas de personas que ha sufrido diversos tipos de violencia, sino también como víctimas directas, cuyos cuerpos fueron convertidos en una estrategia militar de ataque en contra del enemigo. Los tipos de violencia sexual que han padecido, las ha enfrentado a una cultura que rechaza a las víctimas de la misma y a un sistema judicial que no posee los elementos suficientes para bríndales la atención que necesitan.

Aunque se identifica la existencia de diversas estrategias de protección hacia las mujeres víctimas de los grupos armados y de las fuerzas del Estado, como lo son la Unidad para la Atención y la Reparación Integral a las 
Víctimas, diversas leyes sobre el acceso a la justicia, instrumentos jurídicos internacionales como los Convenios de Ginebra o los Pactos internacionales de Derechos Humanos; esta población no ha obtenido la atención y reparación que requiere para superar los estragos sufridos por la violencia. Aun con la presencia en el territorio nacional de diversas organizaciones no gubernamentales y organizaciones internacionales, como la Cruz Roja y ONU Mujeres, la misma evolución del conflicto y dinámicas de violencia, y su duración en el tiempo dificultan una completa satisfacción a sus derechos como víctimas.

Los análisis presentados muestran claramente que la efectividad de las estrategias aplicadas a lo largo del territorio no es buena. Se identifica inicialmente que existe un subregistro de los casos, pues las víctimas no denuncian los delitos cometidos en su contra, ya sea por el desconocimiento de los procesos, la no existencia de los mismos, el miedo que infunden los mismos actores armados o los riesgos que corren de no ser atendidas o ser revictimizadas. Aquellas mujeres que realizan las denuncias pertinentes, se encuentran con un sistema judicial que les brinda poca atención, que las estigmatiza por la violencia sufrida o que no aplica sanciones proporcionales a los daños sufridos. Ante este contexto, las organizaciones no gubernamentales y algunas organizaciones internacionales realizan trabajos enfocados en dar atención a estas mujeres, no obstante, es también una estrategia que se queda corta ante la magnitud del problema y que finalmente está reemplazando una responsabilidad que le corresponde al Estado colombiano.
En consecuencia, se hace necesario que el Estado fortaleza los instrumentos de atención hacia las mujeres víctimas, sea a través de talleres de formación y capacitación que permita que los agentes de la rama judicial consideren el enfoque de género en los procesos de atención que realizan, o por medio de una reforma a la justicia que aplique sanciones más severas hacia los responsables de los delitos. Se evidencia que la legislación a nivel nacional e internacional es existente, pero los fallos en la atención se presentan por la dinámica de funcionamiento de las instituciones, por lo cual se hace necesario su fortalecimiento.

Si se mejora la atención desde las instituciones del Estado es posible reducir el subregistro de los delitos, en el sentido que, si hay mayor efectividad en la atención, una mayor cantidad de víctimas van a acudir al sistema judicial. A esto se debe sumar la necesaria superación de la cultura patriarcal que caracteriza a la sociedad colombiana, tarea que no es fácil, pero que se puede lograr desde el mismo sistema educativo colombiano.

Finalmente, la estrategia que mayor resultado daría para superar la violencia en contra de la mujer en el marco del conflicto armado, es la solución al mismo. Al respecto, el actual acuerdo de paz es un paso importante para este objetivo, no obstante, no es suficiente, más cuando todavía hay presencia de otros grupos armados. Es necesario que el gobierno nacional busque salida a los problemas de violencia con cada uno de los actores armados que permanecen en el territorio, de tal forma que no solo se reduzca la violencia en contra de las mujeres sino en contra de toda la población en general. 


\section{Referencias}

- Abril, R. (2011). Mujer como partícipe y destinatario de las estrategias de paz y seguridad: desarrollos recientes y retos planteados. Revista española de derecho milita, 98(2), 17-80.

- Amnistía Internacional (2004). Cuerpos marcados, crímenes silenciados Violencia sexual contra las mujeres en el marco del conflicto armado. España: Editorial Amnistía Internacional (EDAI). http://www.corteidh.or.cr/ tablas/23128.pdf

- Arnoso, M., Cárdenas, M., Beristain, C. y Afosdo, C. (2017). Armed Conflict, Psychosocial Impact and Reparation in Colombia: Women's Voice. Universitas Psychologica, 16(3), 1-12.

- Centro Nacional de Memoria Histórica (2017). La guerra inscrita en el cuerpo. Informe nacional de violencia sexual en el conflicto armado. CNMH. https://bit.ly/37rSITG

- Chaparro, L. (2013). Acceso a la justicia para mujeres víctimas de violencia sexual Quinto Informe de Seguimiento al Auto 092 de 2008 de la Corte Constitucional. https://bit.ly/2MPz19k

- Constitución de Colombia [Const.]. (1991). Artículos 11, 12, 13, 17, 21 [Título II]. https://bit. ly/30EaCvs

- Grupo de Memoria Histórica. (2013) ¡Basta ya! Colombia, Memorias de Guerra y Dignidad. Imprenta Nacional.

- Ley núm. 1719. Diario Oficial núm. 49.186, Bogotá, Colombia, 18 de junio de 2014.
- Ley núm. 1448. Ley de víctimas y restitución de tierras. Diario Oficial núm. 48.096, Bogotá, Colombia, 10 de junio de 2011.

- Ley núm. 975. Ley de justicia y paz. Diario Oficial núm. 45.980, Bogotá, Colombia, 25 de julio de 2005

- Moncayo, A. (2009). Violencia sexual en el conflicto armado: barreras para acceder a la justicia. Universidad Externado de Colombia.

- Restrepo Yepes, O., (2007). ¿El silencio de las inocentes?: Violencia sexual a mujeres en el contexto del conflicto armado. Opinión jurídica. 6(11), 87-114.

- Sánchez, O., (2008). El cuerpo de las mujeres territorio en disputa por los actores armados. En Sánchez, O. y Gallego, M. (Ed.) Las violencias contra las mujeres en una sociedad en guerra (pp. 65-88). https://bit.ly/37rSBSE

- Unidad para la Atención y la Reparación Integral a las Víctimas (2020). Registro Único de Víctimas. https://bit.ly/2UGFo2S

- Unidad para la Atención y la Reparación Integral a las Víctimas (2018). Estrategia de reparación integral a mujeres víctimas de violencia sexual. https://bit.ly/30E78sH

- Unidad para la Atención y la Reparación Integral a las Víctimas (s.f). Mujeres y conflicto armado. https://bit.ly/3cWxFEq

- Wilches, I. (2010). Lo que hemos aprendido sobre la atención a mujeres víctimas de violencia sexual en el conflicto armado colombiano. Revista de estudios sociales, (36), 86-94. 